\title{
Immunomodulation as a Potent COVID-19 Pharmacotherapy: Past, Present and Future
}

\author{
Decsa Medika Hertanto 1,2 \\ Bayu Satria Wiratama ${ }^{3,4}$ \\ Henry Sutanto $\mathbb{1}^{5,6}$ \\ Citrawati Dyah Kencono \\ Wungu $\mathbb{1 D}^{7,8}$
}

'Department of Internal Medicine, Faculty of Medicine, Airlangga University, Surabaya, Indonesia; ${ }^{2}$ Department of Internal Medicine, Dr. Soetomo General Hospital, Surabaya, Indonesia;

${ }^{3}$ Department of Epidemiology,

Biostatistics, and Population Health, Faculty of Medicine, Public Health and Nursing, Universitas Gadjah Mada, Yogyakarta, Indonesia; ${ }^{4}$ Graduate Institute of Injury Prevention and Control, College of Public Health, Taipei Medical University, Taipei, Taiwan; ${ }^{5}$ Department of Cardiology, CARIM School for Cardiovascular Diseases, Maastricht University, Maastricht, the Netherlands; ${ }^{6}$ Department of Physiology and Pharmacology, State University of New York (SUNY) Downstate Health Sciences University, New York, NY, USA; ${ }^{7}$ Department of Physiology and Medical Biochemistry, Faculty of Medicine, Airlangga University, Surabaya, Indonesia; ${ }^{8}$ Institute of Tropical Disease, Airlangga University, Surabaya, Indonesia
Correspondence: Citrawati Dyah Kencono Wungu Department of Physiology and Medical Biochemistry, Faculty of Medicine, Airlangga University, Surabaya, Indonesia Email citrawati.dyah@fk.unair.ac.id

\begin{abstract}
In the first year of its appearance, the 2019 coronavirus disease (COVID-19) has affected more than 150 million individuals and killed 3 million people worldwide. The pandemic has also triggered numerous global initiatives to tackle the newly emerging disease, including the development of SARS-CoV-2 vaccines and the attempt to discover potential pharmacological therapies. Nonetheless, despite the success of SARS-CoV-2 vaccine development, COVID-19 therapy remains challenging. Several repurposed drugs that were documented to be useful in small clinical trials have been shown to be ineffective in larger studies. Additionally, the pathophysiology of SARS-CoV-2 infection displayed the predominance of hyperinflammation and immune dysregulation in inducing multiorgan damage. Therefore, the potential benefits of both immune modulation and suppression in COVID-19 have been extensively discussed. Here, we reviewed the roles of immunomodulation as potential COVID-19 pharmacological modalities based on the existing data and proposed several new immunologic targets to be tested in the foreseeable future.
\end{abstract}

Keywords: COVID-19, immunomodulation, immunology, immune system, pharmacotherapy, coronavirus, drug repurposing

\section{Introduction}

The 2019 coronavirus disease (COVID-19) is caused by severe acute respiratory syndrome-associated coronavirus type-2 (SARS-CoV-2) infection. In the first year of its appearance, COVID-19 has affected more than 150 million individuals and killed 3 million people worldwide. In some countries, the numbers are still soaring, while in some of the others, the cases are resurging, entering the second and third waves. Such increase could be attributed to several determinants, including the emergence of novel SARS-CoV-2 variants (eg, N501Y, E484K, B1.1.7), psychological exhaustions (pandemic fatigue) altering the adherence to health protocols, viral reinfection, vaccination delay and the non-existence of potent pharmacological treatments for COVID-19. In most of the contracted patients, COVID-19 is asymptomatic or only causes mild to moderate non-life-threatening symptoms. However, in high-risk individuals, it can cause serious conditions, leading to severe acute respiratory failure, multiorgan dysfunction and death. Therefore, having safe and effective pharmacological agents for COVID-19 is essential to prevent mortality and COVID-19-associated complications (eg, long COVID).

The recently emerged disease has triggered numerous global initiatives, including the development of SARS-CoV-2 vaccines and the attempt to discover potential pharmacological therapies. Nonetheless, despite the success of SARS-CoV-2 vaccine 
development, COVID-19 therapy remains challenging. Several repurposed drugs that were documented to be useful in small clinical trials were ineffective in larger studies. For example, the antimalarial drug chloroquine and antimicrobial azithromycin were effective in reducing COVID-19associated mortality in a non-randomized, retrospective, multicenter study involving 2541 patients. ${ }^{1}$ However, in a meta-analysis, the chloroquine and azithromycin-treated group displayed no significant difference in mortality compared to standard care. ${ }^{2}$ Moreover, several randomized control trials (RCTs) indicated that chloroquine with/without azithromycin was not effective in improving clinical outcomes $^{3-5}$ or as post-exposure prophylaxis. ${ }^{6}$ Moreover, those drugs were associated with greater adverse effects, including the occurrence of malignant arrhythmias. ${ }^{7}$ Similarly, the use of human immunodeficiency virus protease inhibitors ritonavir/lopinavir was no longer recommended following studies reporting no benefit compared to standard care. $^{8,9}$ Meanwhile, for months, no large RCTs reported the benefits of antiparasitic ivermectin and antiviral favipiravir in COVID-19, although some small studies reported conflicting results for ivermectin ${ }^{10,11}$ and favipiravir. ${ }^{12,13}$ For example, in an RCT involving 400 adult patients with mild COVID-19, no clinical improvement was observed in patient receiving ivermectin compared to placebo. ${ }^{10}$ To date, only antiviral remdesivir was shown to facilitate significant clinical improvements and has been authorized for COVID-19 by major drug safety regulators. ${ }^{14,15}$

Likewise, the pathophysiology and key determinants of the disease have not been fully elucidated. Several data pointed toward the strong involvement of proinflammatory mediators (Figure 1), with evidences of cytokine release syndrome (ie, life-threatening systemic hyperinflammation and immune dysregulation) which are essential to induce multiorgan dysfunction and failure, worsening the prognosis of COVID-19. ${ }^{16,17}$ Therefore, immunosuppression could potentially be beneficial in the COVID-19 management. ${ }^{18}$ However, previous systematic review reported that immunocompromised patients with COVID-19 had higher comorbidities, rates of intensive care and hospital mortality, ${ }^{19}$ indicating the potential risk of immunosuppression in COVID-19. Thus, in this narrative review, we explore the documented effects of immunosuppressive

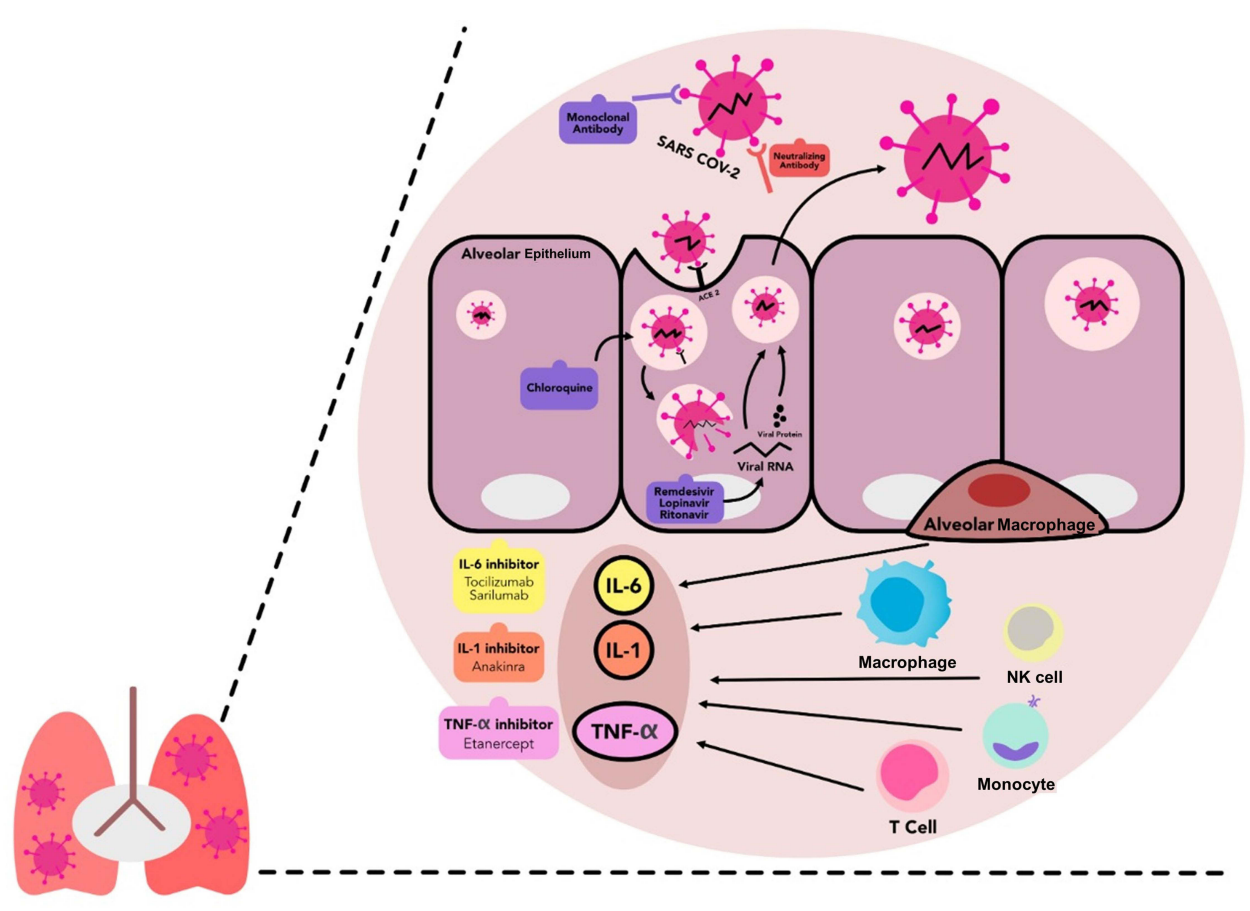

Figure I The entry process of SARS-CoV-2 into alveolar epithelial cells, immune response activation and druggable immunologic targets in COVID-I9. The SARS-CoV-2 enters the infected person via the respiratory tract and attaches to the ACE2 receptors in type- 2 alveolar cells of the lungs. It subsequently activates the retinoic acid inducible gene-(RIG) l-like receptors (RLRs), which play an essential role in the activation of antiviral immune responses. Together with the intrinsic response to the viral particles, they induce hyperactive inflammatory response, marked by the activation of proinflammatory cytokines-releasing cells. Several immunologic targets were identified to have an important role in the COVID-19-mediated immune dysregulation, therefore some pharmacological agents are repurposed to reduce the COVID-19-induced hyperinflammation and to prevent the viral entry and replications.

Abbreviations: ACE2, angiotensin converting enzyme type-2; CoV, coronavirus; IL, interleukin; SARS, severe acute respiratory syndrome; NK, natural killer; TNF, tumour necrosis factor. 
medications (eg, corticosteroids, interleukin (IL)-1 inhibitors, IL-6 inhibitors and kinase inhibitors) and immunomodulators (eg, interferon alpha (IFN $\alpha$ ), interferon beta (IFN $\beta$ ), nonSARS-CoV-2 specific immunoglobulin and convalescent plasma) (Table 1) in COVID-19 and propose some potential immunologic targets to test in the foreseeable future.

\section{Immunosuppression in COVID-I 9}

Hyperactivation of immune system is a hallmark of COVID-19 severity. Ample evidences have reported higher number of leukocytes, increased levels of procalcitonin, C-reactive protein (CRP), and other proinflammatory cytokines (eg, IL-1 and IL-6)/chemokines (eg, CXCL10 and CCL2) in COVID-19 patients requiring intensive care. Such hyperactive inflammatory response initiates cytokine release syndrome and may contribute to the uncontrolled apoptosis, vascular leakage, thromboembolism, multiorgan damage and death. ${ }^{16}$ Therefore, immunosuppression has been proposed as a potential therapeutic strategy in COVID-19.

Table I A Summary of Landmark RCTs Reporting the Effects of Immunomodulation in COVID-19 Management

\begin{tabular}{|c|c|c|}
\hline Investigators & Sample Size and Characteristics & Results \\
\hline \multicolumn{3}{|c|}{ Corticosteroids } \\
\hline $\begin{array}{l}\text { RECOVERY } \\
\text { (dexamethasone) Horby } \\
\text { et } \mathrm{al}^{22}\end{array}$ & $\begin{array}{l}2104 \text { hospitalized COVID- } 19 \text { patients receiving } \\
\text { dexamethasone and } 4321 \text { patients with usual care }\end{array}$ & $\begin{array}{l}\text { Dexamethasone lowered } 28 \text {-day mortality in patients } \\
\text { receiving either invasive mechanical ventilation or oxygen } \\
\text { alone at randomization, but not among those without } \\
\text { respiratory support. }\end{array}$ \\
\hline CoDEX Tomazini et $\mathrm{al}^{25}$ & $\begin{array}{l}299 \text { COVID-19 patients with moderate/severe ARDS } \\
\text { were randomized (I5I received dexamethasone with } \\
\text { standard care and I } 48 \text { with standard care only) }\end{array}$ & $\begin{array}{l}\text { Dexamethasone plus standard care compared with } \\
\text { standard care alone increased the number of ventilator- } \\
\text { free days over } 28 \text { days in COVID-19 patients with } \\
\text { moderate/severe ARDS. }\end{array}$ \\
\hline REMAP-CAP Angus et a $\left.\right|^{27}$ & $\begin{array}{l}403 \text { suspected or confirmed severe COVID-I9 patients in } \\
\text { the intensive care unit (ICU) (randomly assigned to the } \\
\text { fixed-dose }(n=143) \text {, shock-dependent }(n=152) \text {, and no } \\
\qquad(n=108) \text { hydrocortisone groups }\end{array}$ & $\begin{array}{c}\text { A 7-day fixed-dose hydrocortisone or shock-dependent } \\
\text { hydrocortisone, compared with no hydrocortisone, were } \\
\text { superior in improving organ support-free days within } 21 \\
\text { days in severe COVID-19 patients. }\end{array}$ \\
\hline CAPE COVID Dequin et $\mathrm{al}^{26}$ & $\begin{array}{l}\text { I } 49 \text { critically ill patients with SARS-CoV- } 2 \text { infection and } \\
\text { acute respiratory failure ( } 76 \text { with hydrocortisone and } 73 \\
\text { with placebo) }\end{array}$ & $\begin{array}{l}\text { Low-dose hydrocortisone, compared with placebo, did } \\
\text { not significantly reduce death or persistent respiratory } \\
\text { support at day } 21 \text { in critically ill patients with SARS-CoV-2 } \\
\text { infection and acute respiratory failure. [Early terminated] }\end{array}$ \\
\hline \multicolumn{3}{|c|}{ Interleukin inhibitors } \\
\hline REMAP-CAP Gordon et al ${ }^{32}$ & $\begin{array}{l}353 \text { adult patients with COVID-19, within } 24 \text { hours after } \\
\text { starting organ support in the ICU assigned to tocilizumab, } \\
48 \text { to sarilumab, and } 402 \text { to control. }\end{array}$ & $\begin{array}{l}\text { IL-6 receptor antagonists improved outcomes, including } \\
\text { survival in critically-ill COVID-19 patients receiving organ } \\
\text { support in ICUs. }\end{array}$ \\
\hline $\begin{array}{l}\text { RECOVERY (tocilizumab) } \\
\text { Abani et al. }\end{array}$ & $\begin{array}{l}\text { Hospitalized COVID-19 patients with hypoxia and } \\
\text { systemic inflammation were randomly allocated to } \\
\text { tocilizumab }(n=2022) \text { and to usual care }(n=2094) \text {. }\end{array}$ & $\begin{array}{l}\text { Tocilizumab improved survival and other clinical outcomes } \\
\text { in hospitalized COVID-19 patients with hypoxia and } \\
\text { systemic inflammation. }\end{array}$ \\
\hline COVACTA Rosas et al ${ }^{36}$ & $\begin{array}{c}438 \text { hospitalized patients with severe COVID-19 } \\
\text { pneumonia (294 in the tocilizumab group and I44 in the } \\
\text { placebo group) }\end{array}$ & $\begin{array}{l}\text { Tocilizumab did not significantly improve clinical status or } \\
\text { lower mortality than placebo at } 28 \text { days in hospitalized } \\
\text { patients with severe COVID-19 pneumonia. }\end{array}$ \\
\hline $\begin{array}{l}\text { Boston Area COVID- } 19 \\
\text { Consortium (BACC) Bay } \\
\text { Tocilizumab Trial Stone et } \mathrm{al}^{37}\end{array}$ & $\begin{array}{l}243 \text { patients with confirmed SARS-CoV-2 infection, } \\
\text { hyperinflammatory states, and at least two of the following } \\
\text { signs: fever, pulmonary infiltrates, or the need for } \\
\text { supplemental oxygen ( } 16 \mid \text { received tocilizumab and } 81 \\
\text { received placebo) }\end{array}$ & $\begin{array}{l}\text { Tocilizumab was not effective for preventing intubation or } \\
\text { death in moderately-ill hospitalized patients with COVID- } \\
\qquad 19 .\end{array}$ \\
\hline
\end{tabular}


Table I (Continued).

\begin{tabular}{|c|c|c|}
\hline Investigators & Sample Size and Characteristics & Results \\
\hline EMPACTA Salama et $\mathrm{al}^{38}$ & $\begin{array}{c}389 \text { hospitalized patients with COVID-19 pneumonia who } \\
\text { were not receiving mechanical ventilation ( } 249 \text { with } \\
\text { tocilizumab and } 128 \text { with placebo) }\end{array}$ & $\begin{array}{l}\text { Tocilizumab reduced the likelihood of progression to the } \\
\text { composite outcome of mechanical ventilation or death, } \\
\text { but it did not improve survival in hospitalized patients with } \\
\text { COVID-19 pneumonia who were not receiving mechanical } \\
\text { ventilation. }\end{array}$ \\
\hline \multicolumn{3}{|c|}{ Kinase inhibitors } \\
\hline $\begin{array}{l}\text { ACTT-I (baricitinib/ } \\
\text { remdesivir) Kalil et } \mathrm{al}^{42}\end{array}$ & $\begin{array}{l}\text { I033 hospitalized COVID-19 patients underwent } \\
\text { randomization (with } 515 \text { assigned to combination } \\
\text { treatment and } 518 \text { to remdesivir alone) }\end{array}$ & $\begin{array}{l}\text { Baricitinib/remdesivir was superior than remdesivir alone } \\
\text { in facilitating recovery and accelerating improvement in } \\
\text { clinical status among COVID-19 patients, especially with } \\
\text { high-flow oxygen or noninvasive ventilation. The } \\
\text { combination was also associated with fewer major adverse } \\
\text { events. }\end{array}$ \\
\hline \multicolumn{3}{|c|}{ Interferons } \\
\hline Davoudi-Monfared et $\mathrm{al}^{45}$ & $\begin{array}{l}42 \text { severe COVID-I9 patients received IFN } \beta \text {-Ia in } \\
\text { addition to the national protocol medications } \\
\text { (hydroxychloroquine plus lopinavir-ritonavir or atazanavir- } \\
\text { ritonavir) and } 39 \text { patients received only the national } \\
\text { protocol medications (control) }\end{array}$ & $\begin{array}{l}\text { IFN significantly increased discharge rate at day } 14 \text { and } \\
\text { decreased } 28 \text {-day mortality in severe COVID-19 patients } \\
\text { but did not change the time to reach the clinical response. }\end{array}$ \\
\hline $\begin{array}{l}\text { WHO SOLIDARITY Pan } \\
\text { et } \mathrm{al}^{46}\end{array}$ & $\begin{array}{c}\text { II,330 hospitalized COVID-19 adults underwent } \\
\text { randomization; } 2750 \text { received remdesivir, } 954 \text { with } \\
\text { hydroxychloroquine, I4II with lopinavir (without IFN), } \\
2063 \text { with IFN (including } 65 \text { I IFN plus lopinavir), and } 4088 \\
\text { with no trial drug }\end{array}$ & $\begin{array}{l}\text { IFN had no effect on hospitalized patients with COVID-I9, } \\
\text { as indicated by overall mortality, initiation of ventilation, } \\
\text { and duration of hospital stay. }\end{array}$ \\
\hline \multicolumn{3}{|c|}{ Hyperimmune globulin and convalescent plasma } \\
\hline $\begin{array}{l}\text { RECOVERY (convalescent } \\
\text { plasma) Abani et al. }{ }^{51}\end{array}$ & $\begin{array}{l}\text { Of II,558 hospitalized COVID-I9 patients, } 5795 \text { were } \\
\text { randomly assigned to the convalescent plasma and } 5763 \text { to } \\
\text { the usual care groups }\end{array}$ & $\begin{array}{l}\text { High-titer convalescent plasma did not improve survival or } \\
\text { other pre-specified clinical outcomes in hospitalized } \\
\text { COVID-19 patients. }\end{array}$ \\
\hline PLACID Agarwal et $\mathrm{al}^{52}$ & $\begin{array}{l}464 \text { moderate COVID-19 adults ( } 235 \text { with convalescent } \\
\text { plasma and best standard of care and } 229 \text { with best } \\
\text { standard of care only) }\end{array}$ & $\begin{array}{l}\text { Convalescent plasma was not associated with a reduction } \\
\text { in progression to severe COVID-19 or all-cause mortality. }\end{array}$ \\
\hline PlasmAr Simonovich et al. ${ }^{53}$ & $\begin{array}{c}\text { Hospitalized adult patients with severe COVID-19 } \\
\text { pneumonia (228 received convalescent plasma and } 105 \\
\text { received placebo) }\end{array}$ & $\begin{array}{l}\text { No significant differences were observed in clinical status } \\
\text { or overall mortality between patients treated with } \\
\text { convalescent plasma and those who received placebo. }\end{array}$ \\
\hline \multicolumn{3}{|c|}{ Non-SARS-CoV-2 specific intravenous immunoglobulin } \\
\hline Gharebaghi et al. ${ }^{59}$ & $\begin{array}{c}\text { Severe COVID- } 19 \text { patients who did not respond to initial } \\
\text { treatments ( } 30 \text { received IVIg and } 29 \text { patients received } \\
\text { placebo) }\end{array}$ & $\begin{array}{l}\text { IVIg improved clinical outcome and significantly reduced } \\
\text { mortality rate in severe COVID-I9 patients who did not } \\
\text { respond to initial treatment. }\end{array}$ \\
\hline
\end{tabular}

Corticosteroids have a potent anti-inflammatory effect and are currently being used to treat dysregulated inflammatory response in autoimmune diseases. In COVID-19, inhaled corticosteroid ciclesonide inhibited SARS-CoV-2 ribonucleic acid (RNA) replication by targeting viral replication-transcription complex..$^{20}$ Despite the failure of corticosteroids to show significant benefits and their association with delayed viral clearance in previous coronavirus (SARS-CoV-1 and MERS-CoV) diseases, studies investigating the effects of corticosteroids in COVID-19 showed several promising results. ${ }^{21}$ For example, methylprednisolone lowered COVID-19-associated mortality in patients with acute respiratory distress syndrome and reduced the duration of supplemental oxygen in COVID-19 patients. ${ }^{21}$ More recently, Randomized Evaluation of COVID19 Therapy (RECOVERY) trial, a randomized controlled open-label trial, reported that dexamethasone lowered the 28day mortality among patients receiving invasive mechanical ventilation ( $\mathrm{RR} 0.65$; $[95 \% \mathrm{CI}=0.48-0.88] ; \mathrm{p}=0.0003$ ) and among those receiving oxygen without invasive mechanical ventilation $(0.80 ;[0.67-0.96] ; \mathrm{p}=0.0021)$, but not among those 
who received no respiratory support $(1.22 ;[0.86$ to 1.75$]$; $\mathrm{p}=0.14)$. The study was performed on 2104 patients who were randomized and given dexamethasone $6 \mathrm{mg}$ once daily for ten days, either orally or by intravenous injection, and compared with 4321 patients receiving standard therapy. The study also showed that dexamethasone lowered 28-day mortality by $17 \%(0.83 ;[0.74-0.92] ; \mathrm{P}=0.0007) .{ }^{22}$ Consistently, a meta-analysis of 7 RCTs, such as the ongoing DEXACOVID19, ${ }^{23}$ ongoing COVID STEROID, ${ }^{24}$ CoDEX, $^{25}$ RECOVERY, $^{22}$ CAPE COVID, ${ }^{26}$ REMAP-CAP ${ }^{27}$ and unpublished Steroids-SARI, concluded that corticosteroids compared with usual care or placebo lowered the 28-day all-cause mortality. ${ }^{28}$ However, in adults with non-severe COVID-19, corticosteroid therapy was associated with worse clinical outcomes, ${ }^{29}$ a higher risk of progression of severity and prolonged hospital stay, ${ }^{21}$ highlighting the potential benefits of corticosteroids in the treatment of moderate/severe COVID-19 patients. Additionally, a recent retrospective study reported that delayed SARS-CoV-2 clearance observed in moderate/ severe COVID-19 was not associated with an early use of corticosteroids. $^{30}$

Interleukin inhibitors are commonly prescribed in autoimmune diseases and other hyperinflammatory states. Several interleukins are responsible for COVID-19mediated cytokine releases (eg, IL-1 $\beta$, IL-6 and IL-18) and their inhibition could be beneficial. A cohort of 117 patients with respiratory insufficiency and hyperinflammation receiving either IL-1 or IL-6 inhibitors reported that IL1 inhibition (with anakinra) significantly reduced mortality in COVID-19 patients with respiratory insufficiency and hyperinflammation. Meanwhile, IL-6 inhibition (with tocilizumab or sarilumab) was only effective in a subgroup of patients with high CRP or low lactate dehydrogenase. ${ }^{31}$ Additionally, in the Randomized, Embedded, Multifactorial Adaptive Platform Trial for CommunityAcquired Pneumonia (REMAPCAP), IL-6 inhibitors also improved survivals in critically ill COVID-19 patients receiving intensive organ support. ${ }^{32}$ The RECOVERY trial, a large randomized, controlled, open-label, platform trial, which enrolled 4116 patients, reported that tocilizumab could increase the probability of patients discharged alive from hospital within 28 days ( $57 \%$ vs $50 \% ; 1.22 ; 95 \%$ $\mathrm{CI}=1.12-1.33 ; \mathrm{p}<0.0001)$. Tocilizumab also reduced the 28-days mortality in severe COVID-19 patients as compared to standard therapy alone $(0.86 ; 95 \% \mathrm{CI}=0.77$ $0.96 ; \mathrm{p}=0.007$ ). ${ }^{33}$ Moreover, in a meta-analysis of 71 (heterogenous) studies, tocilizumab was consistently associated with a lower relative risk of mortality in prospective studies, but effects were inconclusive for other outcomes. ${ }^{34}$ Another meta-analysis involving large-scale studies showed that tocilizumab may have substantial effectiveness in reducing mortality among COVID-19 patients, especially among critical cases, ${ }^{35}$ underlining the prospective benefits of IL inhibition in COVID-19. Nevertheless, in the COVACTA trial, an RCT involving 452 hospitalized patients with severe COVID-19-associated pneumonia, the use of tocilizumab did not significantly improve clinical status or lower mortality than placebo at 28 days. ${ }^{36}$ Another randomized double-blind, placebo-controlled trial (Boston Area COVID-19 Consortium Bay Tocilizumab Trial) showed that tocilizumab was not effective in preventing intubation or mortality in moderately ill hospitalized COVID-19 patients. $^{37}$ Meanwhile, the EMPACTA (Evaluating Minority Patients with Actemra) study, a global, Phase 3 clinical trial, reported that in 249 hospitalized patients with COVID-19-associated pneumonia without mechanical ventilation, tocilizumab did not improve survival, although it reduced the likelihood of progression to the composite outcome of mechanical ventilation or death. ${ }^{38}$ These studies suggested that tocilizumab may exhibit different clinical outcomes depending on the severity of COVID-19 and the need for mechanical ventilation.

Kinase inhibitors inhibit numerous kinases that are important for viral infection (eg, ABL, numb-associated kinase, cyclin-dependent kinase, phosphoinositide 3 kinase/protein kinase $\mathrm{B} /$ mechanistic target of rapamycin [mTOR], extracellular signal-regulated kinase/mitogen-activated protein kinase and janus kinase [JAK]) and predicted to be involved in mediating infection by SARS-CoV-2. ${ }^{39}$ They play important roles in viral entry, intracellular membrane trafficking, viral replication and viral life cycle, and possess an immunomodulatory effect that could be useful against COVID-19-mediated hyperactive immune response. However, a recent in-vitro study showed that imatinib, an ABL inhibitor, did not inhibit SARS-CoV-2 entry/infection and replication. ${ }^{40}$ Meanwhile, baricitinib, a JAK inhibitor, prevented phosphorylation of key proteins involved in the signal transduction that leads to immune activation and inflammation (eg, the cellular response to IL-6). ${ }^{41}$ In a double-blind, randomized, placebo-controlled trial of 1033 patients, baricitinib/remdesivir was superior to remdesivir alone in reducing recovery time and accelerating clinical improvement, and associated with fewer serious adverse events in COVID-19 patients receiving high-flow oxygen or non-invasive ventilation. ${ }^{42}$ 


\section{Immune System Modulation in COVID-I 9}

In addition to immunosuppression, several immunomodulators are proposed in COVID-19 management and expected to restore the immunologic homeostasis in COVID-19 patients. $^{18}$

Interferons are cytokines-made and released by host cells in response to viral pathogens. SARS-CoV-2 could escape innate immunity early during the infection by altering intrinsic IFN effect in limiting viral replication and spread. ${ }^{43}$ In a retrospective cohort of 77 adults with moderate COVID-19, treatments using nebulized IFN $\alpha-2 b$ yielded a shorter time to viral clearance from the upper respiratory tract and a reduction in systemic inflammation. ${ }^{44}$ In a randomized controlled trial of 42 patients receiving subcutaneous IFN $\beta$-1a on top of hydroxychloroquine/lopinavir/ritonavir or atazanavir/ritonavir therapies, IFN $\beta$-1a significantly increased discharge rate at day-14 and reduced 28-day mortality. ${ }^{45}$ However, the interim results of the World Health Organization (WHO) Solidarity trial displayed no difference in mortality rate between patients administered with IFN $\beta$ - $1 \mathrm{a}$ and standard care $(1.16 ; 95 \% \mathrm{CI}=0.96-$ 1.39; $\mathrm{P}=0.11) .{ }^{46}$ More data investigating the effects of IFN are required due to an increasing evidence that patients with severe COVID-19 have a robust type-I IFN response, in contrast with the delayed, possibly suppressed, IFN response in the early phase of SARS-CoV-2 infection. ${ }^{47}$

Hyperimmune globulin and convalescent plasma are derived from individuals with high antibody titers to specific pathogens and can provide passive immunity (ie, neutralizing antibodies) against particular infectious agents. It was effective in treating SARS-CoV-1 and MERS-CoV infections by increasing the discharge rate and lowering mortality. ${ }^{48}$ In a retrospective, propensity score-matched case-control study in 39 patients with severe or life-threatening COVID-19, convalescent plasma reduced the oxygen requirements at day- 14 after transfusion and improved survivals. ${ }^{49}$ Another retrospective multicenter observational study also showed that patients who had an early initiation of plasma therapy displayed a shorter duration of hospitalization (12.7 vs 24.3 days, $p=$ 0.000). ${ }^{50}$ Interestingly, such observation was not documented in RCTs, including the RECOVERY trial, in which high-titer convalescent plasma did not improve survival or other prespecified clinical outcomes. ${ }^{51}$ A meta-analysis of 10 RCTs, including PLACID ${ }^{52}$ and $\mathrm{PlasmAr}^{53}$ trials also reported that the treatment with convalescent plasma compared to placebo or standard care was not significantly associated with a decrease in all-cause mortality or with any benefit for other clinical outcomes. ${ }^{54}$ Since the majority of the RCTs also involved moderate to severe COVID-19 patients, this finding discrepancy might not be due to the difference in disease severity. Nonetheless, convalescent plasma may still be an alternative in COVID-19 patients with specific comorbidities. For example, in a cohort study, an early administration of convalescent plasma improved survival in COVID-19 patients with hematological malignancies. ${ }^{55}$ Additionally, in a nationwide observational multicenter study, the administration of convalescent plasma improved clinical outcomes in B-cell-depleted patients with protracted COVID-19. ${ }^{56}$ Overall, these data suggested that application of convalescent plasma in COVID-19 might be limited.

Non-SARS-CoV-2 specific intravenous immunoglobulin (IVIg) is a product derived from the pooled plasma of donors that provides passive immunity against a broad range of pathogens and commonly used for treatment of primary and secondary immunodeficiencies, autoimmune/inflammatory conditions, neuro-immunologic disorders, and infectionrelated sequelae. ${ }^{48}$ In autoimmune diseases, IVIg modulates the activation and effector functions of B and T lymphocytes, neutralizes pathogenic autoantibodies, interferes with antigen presentation and, therefore, has a strong anti-inflammatory effect. ${ }^{57}$ In COVID-19, although the exact mechanism of action is unclear, it is hypothesized that IVIg exerts its beneficial effect through the modulation of inflammation, including the presence of anti-idiotypic antibodies and $\operatorname{IgG}$ dimers blocking the FcyR activation on innate immune effector cells, ${ }^{48}$ complement scavenging, and reciprocal regulation of effector Th1, Th17 and regulatory T-cells. Moreover, IVIg also decreased plasma IL-6 and CRP levels. ${ }^{58}$ A doubleblind randomized placebo-controlled trial involving 59 patients with severe COVID-19 who did not respond to initial treatments reported an improvement in clinical outcome and a reduction in mortality following the administration of IVIg. ${ }^{59}$ Similarly, several retrospective studies also reported the benefits of early IVIg in reducing the 28-day and 60-day mortality, hospital stay, inflammatory response, and improving multiorgan physiology and clinical outcome of severe COVID-19 patients, ${ }^{58}$ which effects are more prominent in those having no comorbidities or being treated at an earlier stage. $^{60}$

\section{Phase Identification is the Key to a Prompt Immune Modulation}

The majority of previous clinical trials indicated that both immunosuppression and immunomodulation were effective 
in severe/critical COVID-19 conditions requiring respiratory support and ventilation, while in non-severe disease, immunologic treatments might elicit worse outcome (eg, corticosteroid) or no significant improvements in clinical outcome or mortality (Table 1). WHO guideline also strongly recommends systemic corticosteroid administration (ie, dexamethasone, hydrocortisone or prednisone) in patients with severe and critical COVID-19 either orally or intravenously, while in nonsevere COVID-19 patients, WHO advises against the use of corticosteroids unless the patient is already taking this medication for pre-existing conditions. ${ }^{61}$ This fits well with the identified disease pathophysiology (Figure 2) implying the hyperinflammatory state with cytokine release syndrome in severe COVID-19. In such conditions, inhibition of proinflammatory cytokines with immunosuppressive agents could reduce the damaging consequences of rogue inflammation, and immunomodulation might restore the host immune regulation. On the other hand, in the early phase, immunologic treatments tend to disrupt the activation of immune response against viruses and, therefore, could be detrimental. Tailoring treatments in line with the phase of COVID-19 disease course is critically important and supported by data from major clinical trials. For example, in the Adaptive COVID-19 Treatment Trial (ACTT-1), remdesivir was shown to work best in the early phase of the disease, while the RECOVERY trial indicated that dexamethasone was best administered in the late phase. ${ }^{14,22}$ Nonetheless, the roles of immune system modulation in COVID-19 caused by recently emerged SARS-CoV-2 variants (B1.1.7, B.1.1.7/E484K, B.1.351 and P.1) remain unknown. Those variants resulted in a higher mortality than the original SARS-CoV-2 ${ }^{62}$ and could possess distinct responses to immune-based therapy, although further research is warranted.

\section{Future Immunologic Targets for COVID-19}

In the future, several novel immunologic targets, such as tumor necrosis factor (TNF)- $\alpha$ inhibitors, retinoic acidinducible gene I-like receptor (RLR) and mTOR inhibitors, NLRP3 inflammasome inhibitors, complement inhibitors, toll-like receptor modulators, IL-18 inhibitors and possibly mesenchymal stem-cell secretome may be tested due to their reported significance in COVID-19 pathogenesis.

A few studies have shown that TNF- $\alpha$ inhibition reduced mortality and hospital admission in COVID-19 patients. ${ }^{63}$ In a group of patients with inflammatory bowel disease and COVID-19, TNF- $\alpha$ inhibition was inversely associated with the composite outcome of death or hospital admission for

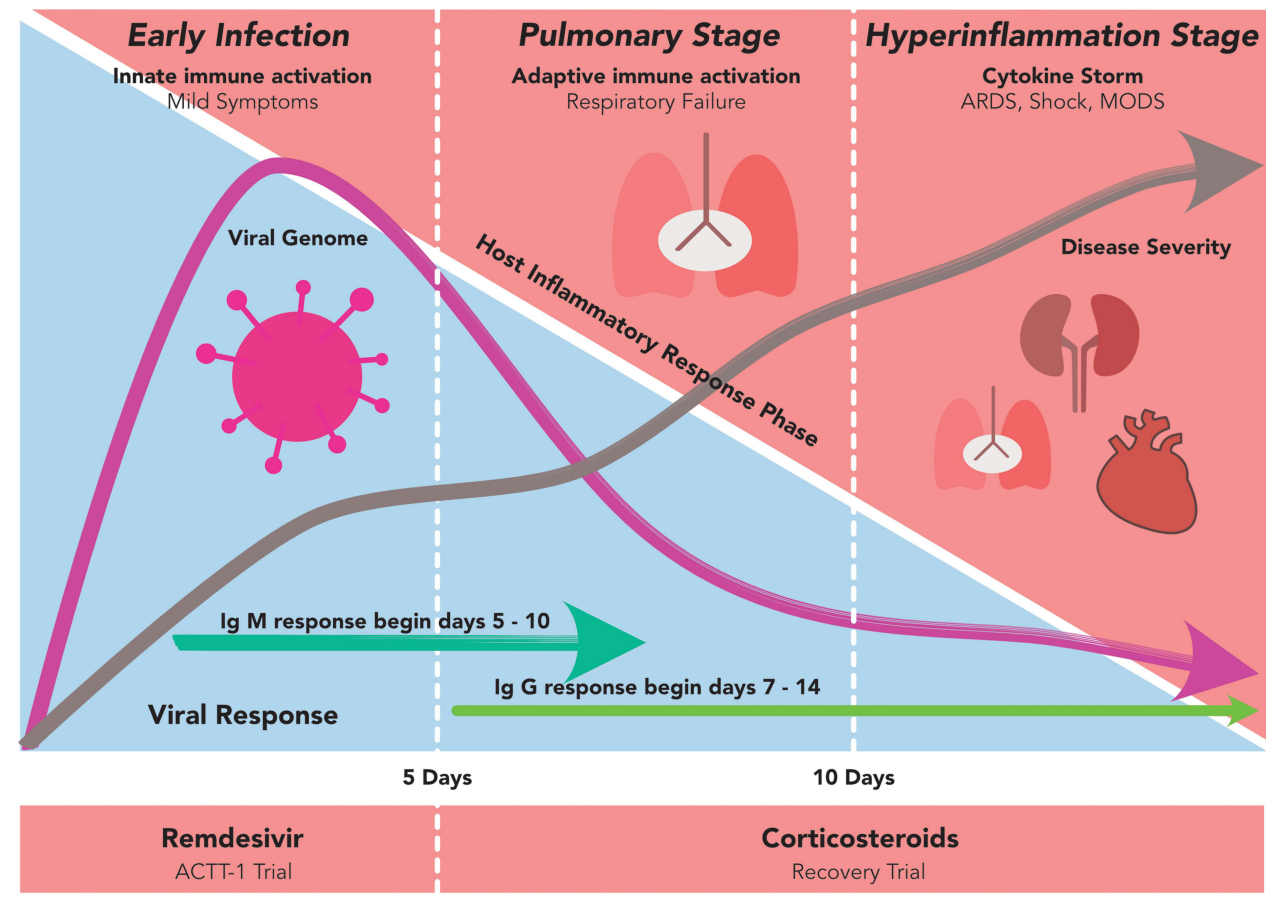

Figure 2 The phases of COVID-19. The COVID-19 can be divided into 3 stadiums: the early infection, the pulmonary and the hyperinflammation stages. In the early infection, the viral load (purple line in the blue zone) starts to increase and at some points, it begins to activate the host immune response (red zone). While the disease progresses into a more severe state, the proinflammatory cytokines build up and start to form antibody against the virus. When the disease is not promptly treated, COVID19 may fall into the hyperinflammation stage, multiorgan failure and death.

Abbreviations: ARDS, acute respiratory distress syndrome; MODS, multiorgan dysfunction syndrome. 
COVID-19. ${ }^{64}$ Moreover, among others, data from 600 rheumatic patients with COVID-19 showed that TNF- $\alpha$ inhibitor, either alone or in combination with other immunomodulatory drugs, was associated with a lower rate of hospital admission for COVID-19. ${ }^{63,65}$ However, those studies were conducted in patients with immunologic disorders who perhaps already developed chronic immune system remodeling, thus might provide distinct immune response against SARS-CoV-2 infection. Hence, further clinical study on the efficacy of TNF- $\alpha$ inhibitors in COVID-19 patients without immune-related comorbidities is warranted.

Complement system inhibition is also a potential therapeutic target for COVID-19. Preliminary data by Gao et al demonstrated the presence of complement hyperactivation (eg, widespread C3 and C5 complements deposition) in COVID$19^{66}$ and the activation, either through classical or alternative routes, can contribute to the maladaptive inflammatory response, escalating the infection severity. ${ }^{67}$ Therefore, several clinical trials have been initiated to investigate the potential role of complement inhibitors in COVID-19. ${ }^{68}$ For example, the combination of $\mathrm{C} 5$ inhibitor ravulizumab and JAK inhibitor baricitinib, which is now entering the Phase IV clinical trial. $^{69}$

Meanwhile, RLR is activated following the identification of viral RNAs in the cytoplasm of infected cells, initiating the production of type I and III IFNs and inflammatory cytokines. ${ }^{70}$ Therefore, the inhibition of RLR could alter the interactions between host and viral factors, which potentially prevent the activation of excessive inflammatory response in COVID-19. Previous studies also reported the activation of NLRP3 inflammasome in COVID-19, ${ }^{71,72}$ which facilitates the initiation of major proinflammatory cytokines, such as IL-1 $\beta$ and IL-18. Therefore, inhibitions of NLRP3 inflammasome and its downstream mediators (eg, IL-1 $\beta$ and IL-18) could potentially reduce COVID-19-associated morbidity and mortality by minimizing the hyperinflammatory state. Lastly, although it is still in the early phase, the possible contributions of mesenchymal stem cells and their secretome in COVID-19 management are being investigated. ${ }^{73}$ Nonetheless, at present, those potential targets remain at the investigational stage and further extensive experimental and clinical studies are required to evaluate their effectivity in COVID-19.

\section{Conclusions}

Both immunosuppression and immunomodulation could serve as potent COVID-19 pharmacotherapies when they are administered in an appropriate disease stage/severity (Figure 2).
Patients' characteristics and comorbidities have to be considered to minimize adverse effects and complications of immunotherapies. At present, several new pharmacological targets are being investigated and in the near future, they are expected to contribute to the COVID-19 management.

\section{Author Contributions}

All authors made substantial contributions to conception and design, acquisition of data, or analysis and interpretation of data; took part in drafting the article or revising it critically for important intellectual content; agreed to submit to the current journal; gave final approval of the version to be published; and agreed to be accountable for all aspects of the work.

\section{Funding}

There is no funding to report.

\section{Disclosure}

The authors report no conflicts of interest in this work.

\section{References}

1. Arshad S, Kilgore P, Chaudhry ZS, et al. Treatment with hydroxychloroquine, azithromycin, and combination in patients hospitalized with COVID-19. Int $J$ Infect Dis. 2020;97:396-403. doi:10.1016/j. ijid.2020.06.099

2. Ghazy RM, Almaghraby A, Shaaban R, et al. A systematic review and meta-analysis on chloroquine and hydroxychloroquine as monotherapy or combined with azithromycin in COVID-19 treatment. Sci Rep. 2020;10(1):22139. doi:10.1038/s41598-020-77748-x

3. Self WH, Semler MW, Leither LM, et al. Effect of hydroxychloroquine on clinical status at 14 days in hospitalized patients with covid-19: a randomized clinical trial. JAMA. 2020;324 (21):2165-2176. doi:10.1001/jama.2020.22240

4. Reis G, Moreira Silva E, Medeiros Silva DC, et al. Effect of early treatment with hydroxychloroquine or lopinavir and ritonavir on risk of hospitalization among patients with COVID-19: the TOGETHER randomized clinical trial. JAMA Netw Open. 2021;4(4):e216468. doi:10.1001/jamanetworkopen.2021.6468

5. Horby P, Mafham M, Linsell L, et al. Effect of hydroxychloroquine in hospitalized patients with Covid-19. $N$ Engl $J$ Med. 2020;383:2030-2040.

6. Boulware DR, Pullen MF, Bangdiwala AS, et al. A randomized trial of hydroxychloroquine as postexposure prophylaxis for Covid-19. $N$ Engl J Med. 2020;383(6):517-525. doi:10.1056/NEJMoa2016638

7. Sutanto H, Heijman J. Beta-adrenergic receptor stimulation modulates the cellular proarrhythmic effects of chloroquine and azithromycin. Front Physiol. 2020;11:587709. doi:10.3389/fphys.2020.587709

8. Cao B, Wang Y, Wen D, et al. A trial of lopinavir-ritonavir in adults hospitalized with severe Covid-19. $N$ Engl $J$ Med. 2020;382:1787-1799. doi:10.1056/NEJMoa2001282

9. Horby P, Mafham M, Bell L, et al. Lopinavir-ritonavir in patients admitted to hospital with COVID-19 (RECOVERY): a randomised, controlled, open-label, platform trial. Lancet. 2020;396 (10259):1345-1352. doi:10.1016/S0140-6736(20)32013-4

10. Lopez-Medina E, Lopez P, Hurtado IC, et al. Effect of ivermectin on time to resolution of symptoms among adults with mild COVID-19: a randomized clinical trial. JAMA. 2021;325(14):1426. doi:10.1001/ jama.2021.3071 
11. Rajter JC, Sherman MS, Fatteh N, Vogel F, Sacks J, Rajter -J-J. Use of ivermectin is associated with lower mortality in hospitalized patients with coronavirus disease 2019: the ivermectin in COVID Nineteen Study. Chest. 2021;159(1):85-92. doi:10.1016/j.chest.2020.10.009

12. Solaymani-Dodaran M, Ghanei M, Bagheri M, et al. Safety and efficacy of favipiravir in moderate to severe SARS-CoV-2 pneumonia. Int Immunopharmacol. 2021;95:107522. doi:10.1016/j. intimp.2021.107522

13. Cai Q, Yang M, Liu D, et al. Experimental treatment with favipiravir for COVID-19: an Open-Label Control Study. Engineering. 2020;6:1192-1198.

14. Beigel JH, Tomashek KM, Dodd LE, et al. Remdesivir for the treatment of Covid-19 - final report. $N$ Engl J Med. 2020;383 (19):1813-1826. doi:10.1056/NEJMoa2007764

15. Garibaldi BT, Wang K, Robinson ML, et al. Comparison of time to clinical improvement with vs without remdesivir treatment in hospitalized patients with COVID-19. JAMA Netw Open. 2021;4(3): e213071. doi:10.1001/jamanetworkopen.2021.3071

16. Tang Y, Liu J, Zhang D, Xu Z, Ji J, Wen C. Cytokine storm in COVID-19: the current evidence and treatment strategies. Front Immunol. 2020;11:1708. doi:10.3389/fimmu.2020.01708

17. Fajgenbaum DC, June CH, Longo DL. Cytokine storm. $N$ Engl J Med. 2020;383(23):2255-2273. doi:10.1056/NEJMra2026131

18. Bonam SR, Kaveri SV, Sakuntabhai A, Gilardin L, Bayry J. Adjunct immunotherapies for the management of severely Ill COVID-19 patients. Cell Rep Med. 2020;1(2):100016. doi:10.1016/j. xcrm.2020.100016

19. Belsky JA, Tullius BP, Lamb MG, Sayegh R, Stanek JR, Auletta JJ. COVID-19 in immunocompromised patients: a systematic review of cancer, hematopoietic cell and solid organ transplant patients. $J$ Infect. 2021;82(3):329-338. doi:10.1016/j.jinf.2021.01.022

20. Matsuyama S, Kawase M, Nao N, et al. The inhaled steroid ciclesonide blocks SARS-CoV-2 RNA replication by targeting the viral replication-transcription complex in cultured cells. J Virol. 2020;95: e01648-20.

21. Chatterjee K, Wu C-P, Bhardwaj A, Siuba M. Steroids in COVID-19: an overview. Cleve Clin J Med. 2020. doi:10.3949/ccjm.87a.ccc059

22. Horby P, Lim WS, Emberson JR, et al. Dexamethasone in hospitalized patients with Covid-19. N Engl J Med. 2021;384:693-704.

23. Villar J, Anon JM, Ferrando C, et al. Efficacy of dexamethasone treatment for patients with the acute respiratory distress syndrome caused by COVID-19: study protocol for a randomized controlled superiority trial. Trials. 2020;21(1):717. doi:10.1186/s13063-020-04643-1

24. Petersen MW, Meyhoff TS, Helleberg M, et al. Low-dose hydrocortisone in patients with COVID-19 and severe hypoxia (COVID STEROID) trial-protocol and statistical analysis plan. Acta Anaesthesiol Scand. 2020;64:1365-1375. doi:10.1111/aas.13673

25. Tomazini BM, Maia IS, Cavalcanti AB, et al.; Investigators CC-BI. Effect of dexamethasone on days alive and ventilator-free in patients with moderate or severe acute respiratory distress syndrome and COVID-19: the CoDEX randomized clinical trial. JAMA. 2020;324:1307-1316. doi:10.1001/jama.2020.17021

26. Dequin P-F, Heming N, Meziani F, et al.; Group CCT, the C-TN. Effect of hydrocortisone on 21-day mortality or respiratory support among critically ill patients with COVID-19: a randomized clinical trial. JAMA. 2020;324(13):1298-1306. doi:10.1001/ jama.2020.16761

27. Angus DC, Derde L, Al-Beidh F, et al. Effect of hydrocortisone on mortality and organ support in patients with severe COVID-19: the REMAP-CAP COVID-19 corticosteroid domain randomized clinical trial. JAMA. 2020;324(13):1317-1329. doi:10.1001/ jama.2020.17022

28. Sterne JAC, Murthy S, Diaz JV, et al.; Group WHOREAfC-TW. Association between administration of systemic corticosteroids and mortality among critically ill patients with COVID-19: a meta-analysis. JAMA. 2020;324(13):1330-1341. doi:10.1001/jama.2020.17023
29. Li Q, Li W, Jin Y, et al. Efficacy evaluation of early, low-dose, short-term corticosteroids in adults hospitalized with non-severe COVID-19 pneumonia: a Retrospective Cohort Study. Infect Dis Ther. 2020;9(4):823-836. doi:10.1007/s40121-020-00332-3

30. Spagnuolo V, Guffanti M, Galli L, et al., group CO-Bs. Viral clearance after early corticosteroid treatment in patients with moderate or severe covid-19. Sci Rep. 2020;10(1):21291. doi:10.1038/s41598-020-78039-1

31. Cavalli G, Larcher A, Tomelleri A, et al. Interleukin-1 and interleukin-6 inhibition compared with standard management in patients with COVID-19 and hyperinflammation: a cohort study. Lancet Rheumatol. 2021;3(4):e253-e261. doi:10.1016/S2665-9913(21)00012-6

32. Gordon AC, Mouncey PR, Al-Beidh F, et al. Interleukin-6 receptor antagonists in critically ill patients with Covid-19. $N$ Engl $\mathrm{J} \mathrm{Med.}$ 2021;384:1491-1502.

33. Abani O, Abbas A, Abbas F, et al. Tocilizumab in patients admitted to hospital with COVID-19 (RECOVERY): a randomised, controlled, open-label, platform trial. Lancet. 2021;397:1637-1645.

34. Khan FA, Stewart I, Fabbri L, et al. Systematic review and meta-analysis of anakinra, sarilumab, siltuximab and tocilizumab for COVID-19. Thorax. 2021; thoraxjnl-2020-215266. doi:10.1136/ thoraxjnl-2020-215266

35. Wei Q, Lin H, Wei RG, et al. Tocilizumab treatment for COVID-19 patients: a systematic review and meta-analysis. Infect Dis Poverty. 2021;10:71. doi:10.1186/s40249-021-00857-w

36. Rosas IO, Brau N, Waters M, et al. Tocilizumab in hospitalized patients with severe Covid-19 pneumonia. $N$ Engl J Med. 2021;384 (16):1503-1516. doi:10.1056/NEJMoa2028700

37. Stone JH, Frigault MJ, Serling-Boyd NJ, et al.; Investigators BBTT. Efficacy of tocilizumab in patients hospitalized with Covid-19. $N$ Engl J Med. 2020;383:2333-2344. doi:10.1056/NEJMoa2028836

38. Salama C, Han J, Yau L, et al. Tocilizumab in patients hospitalized with Covid-19 pneumonia. N Engl J Med. 2021;384(1):20-30. doi:10.1056/NEJMoa2030340

39. Weisberg E, Parent A, Yang PL, et al. Repurposing of kinase inhibitors for treatment of COVID-19. Pharm Res. 2020;37(9):167. doi:10.1007/s11095-020-02851-7

40. Zhao $\mathrm{H}$, Mendenhall $\mathrm{M}$, Deininger MW. Imatinib is not a potent anti-SARS-CoV-2 drug. Leukemia. 2020;34(11):3085-3087. doi:10.1038/s41375-020-01045-9

41. Zhang W, Zhao Y, Zhang F, et al. The use of anti-inflammatory drugs in the treatment of people with severe coronavirus disease 2019 (COVID-19): the perspectives of clinical immunologists from China. Clin Immunol. 2020;214:108393. doi:10.1016/j.clim.2020.108393

42. Kalil AC, Patterson TF, Mehta AK, et al.; Members A-SG. Baricitinib plus remdesivir for hospitalized adults with Covid-19. N Engl J Med. 2021;384:795-807. doi:10.1056/NEJMoa2031994

43. Calabrese LH, Lenfant $\mathrm{T}$, Calabrese C. Interferon therapy for COVID-19 and emerging infections: prospects and concerns. Cleve Clin J Med. 2020. doi:10.3949/ccjm.87a.ccc066

44. Zhou Q, Chen V, Shannon CP, et al. Interferon-alpha2b treatment for COVID-19. Front Immunol. 2020;11:1061. doi:10.3389/ fimmu.2020.01061

45. Davoudi-Monfared E, Rahmani $\mathrm{H}$, Khalili $\mathrm{H}$, et al. A randomized clinical trial of the efficacy and safety of interferon beta-1a in treatment of severe COVID-19. Antimicrob Agents Chemother. 2020;64. doi:10.1128/AAC.01061-20

46. Pan H, Peto R, Henao-Restrepo AM, et al. Repurposed antiviral drugs for Covid-19 - interim WHO solidarity trial results. $N$ Engl J Med. 2021;384:497-511.

47. Lee JS, Shin E-C. The type I interferon response in COVID-19: implications for treatment. Nat Rev Immunol. 2020;20(10):585-586. doi:10.1038/s41577-020-00429-3

48. Nguyen AA, Habiballah SB, Platt CD, Geha RS, Chou JS, McDonald DR. Immunoglobulins in the treatment of COVID-19 infection: proceed with caution! Clin Immunol. 2020;216:108459. doi:10.1016/j.clim.2020.108459 
49. Liu STH, Lin HM, Baine I, et al. Convalescent plasma treatment of severe COVID-19: a propensity score-matched control study. Nat Med. 2020;26:1708-1713. doi:10.1038/s41591-020-1088-9

50. Jeyaraman P, Agrawal N, Bhargava R, et al. Convalescent plasma therapy for severe Covid-19 in patients with hematological malignancies. Transfus Apher Sci. 2021;60(3):103075. doi:10.1016/ j.transci.2021.103075

51. Abani O, Abbas A, Abbas F, Abbas M, Abbasi S, Zuriaga-Alvaro A, Group RC. Convalescent plasma in patients admitted to hospital with COVID-19 (RECOVERY): a randomised controlled, open-label, platform trial. Lancet. 2021;397:2049-2059.

52. Agarwal A, Mukherjee A, Kumar G, Chatterjee P, Bhatnagar T, Malhotra P. Convalescent plasma in the management of moderate covid-19 in adults in India: open label Phase II multicentre randomised controlled trial (PLACID trial). BMJ. 2020;371:m3939. doi:10.1136/bmj.m3939

53. Simonovich VA, Burgos Pratx LD, Scibona P, et al.; PlasmAr Study G. A randomized trial of convalescent plasma in Covid-19 severe pneumonia. N Engl J Med. 2021;384:619-629. doi:10.1056/NEJMoa2031304

54. Janiaud P, Axfors C, Schmitt AM, et al. Association of convalescent plasma treatment with clinical outcomes in patients with COVID-19: a systematic review and meta-analysis. JAMA. 2021;325:1185-1195. doi:10.1001/jama.2021.2747

55. Biernat MM, Kolasinska A, Kwiatkowski J, et al. Early administration of convalescent plasma improves survival in patients with hematological malignancies and COVID-19. Viruses. 2021;13:436.

56. Hueso T, Pouderoux C, Pere H, et al. Convalescent plasma therapy for B-cell-depleted patients with protracted COVID-19. Blood. 2020;136:2290-2295. doi:10.1182/blood.2020008423

57. Bayry J, Misra N, Latry V, et al. Mechanisms of action of intravenous immunoglobulin in autoimmune and inflammatory diseases. Transfus Clin Biol. 2003;10:165-169. doi:10.1016/ S1246-7820(03)00035-1

58. Galeotti C, Kaveri SV, Bayry J. Intravenous immunoglobulin immunotherapy for coronavirus disease-19 (COVID-19). Clin Transl Immunol. 2020;9(10):e1198. doi:10.1002/cti2.1198

59. Gharebaghi N, Nejadrahim R, Mousavi SJ, Sadat-Ebrahimi S-R, Hajizadeh R. The use of intravenous immunoglobulin gamma for the treatment of severe coronavirus disease 2019: a randomized placebo-controlled double-blind clinical trial. BMC Infect Dis. 2020;20(1):786. doi:10.1186/s12879-020-05507-4

60. Cao W, Liu X, Hong K, et al. High-dose intravenous immunoglobulin in severe coronavirus disease 2019: a Multicenter Retrospective Study in China. Front Immunol. 2021;12:627844. doi:10.3389/ fimmu.2021.627844

61. WHO. COVID-19 Clinical Management: Living Guidance. World Health Organization; 2021.

62. Challen R, Brooks-Pollock E, Read JM, Dyson L, TsanevaAtanasova K, Danon L. Risk of mortality in patients infected with SARS-CoV-2 variant of concern 202012/1: matched cohort study. BMJ. 2021;372:n579. doi:10.1136/bmj.n579
63. Robinson PC, Richards D, Tanner HL, Feldmann M. Accumulating evidence suggests anti-TNF therapy needs to be given trial priority in COVID-19 treatment. Lancet Rheumatol. 2020;2(11):e653-e655. doi:10.1016/S2665-9913(20)30309-X

64. Brenner EJ, Ungaro RC, Gearry RB, et al. Corticosteroids, but not TNF antagonists, are associated with adverse COVID-19 outcomes in patients with inflammatory bowel diseases: results from an international registry. Gastroenterology. 2020;159:481-491 e483. doi:10.1053/j.gastro.2020.05.032

65. Gianfrancesco M, Hyrich KL, Al-Adely S, et al. Characteristics associated with hospitalisation for COVID-19 in people with rheumatic disease: data from the COVID-19 global rheumatology alliance physician-reported registry. Ann Rheum Dis. 2020;79(7):859-866. doi:10.1136/annrheumdis-2020-217871

66. Gao T, Hu M, Zhang X, et al. Highly pathogenic coronavirus $\mathrm{N}$ protein aggravates lung injury by MASP-2-mediated complement over-activation. medRxiv. 2020;2020.

67. Risitano AM, Mastellos DC, Huber-Lang M, et al. Complement as a target in COVID-19? Nat Rev Immunol. 2020;20(6):343-344. doi:10.1038/s41577-020-0320-7

68. Esmaeilzadeh A, Elahi R. Immunobiology and immunotherapy of COVID-19: a clinically updated overview. J Cell Physiol. 2021;236 (4):2519-2543. doi:10.1002/jcp.30076

69. Kulkarni S, Fisk M, Kostapanos M, et al. Repurposed immunomodulatory drugs for Covid-19 in pre-ICu patients - mulTi-arm therapeutic study in pre- $\mathrm{ICu}$ patients admitted with Covid-19 repurposed drugs (TACTIC-R): a structured summary of a study protocol for a randomised controlled trial. Trials. 2020;21(1):626. doi:10.1186/s13063-020-04535-4

70. Onomoto K, Onoguchi K, Yoneyama M. Regulation of RIG-I-like receptor-mediated signaling: interaction between host and viral factors. Cell Mol Immunol. 2021;18:539-555.

71. Rodrigues TS, de Sa KSG, Ishimoto AY, et al. Inflammasomes are activated in response to SARS-CoV-2 infection and are associated with COVID-19 severity in patients. J Exp Med. 2021;218(3). doi:10.1084/jem.20201707

72. Toldo S, Bussani R, Nuzzi V, et al. Inflammasome formation in the lungs of patients with fatal COVID-19. Inflamm Res. 2021;70 (1):7-10. doi:10.1007/s00011-020-01413-2

73. Harrell CR, Jovicic BP, Djonov V, Volarevic V, Amantini C. Therapeutic potential of mesenchymal stem cells and their secretome in the treatment of SARS-CoV-2-induced acute respiratory distress syndrome. Anal Cell Pathol. 2020;2020:1939768. doi:10.1155/2020/ 1939768
Journal of Inflammation Research

\section{Publish your work in this journal}

The Journal of Inflammation Research is an international, peerreviewed open-access journal that welcomes laboratory and clinical findings on the molecular basis, cell biology and pharmacology of inflammation including original research, reviews, symposium reports, hypothesis formation and commentaries on: acute/chronic inflammation; mediators of inflammation; cellular processes; molecular mechanisms; pharmacology and novel anti-inflammatory drugs; clinical conditions involving inflammation. The manuscript management system is completely online and includes a very quick and fair peerreview system. Visit http://www.dovepress.com/testimonials.php to read real quotes from published authors. 